\title{
Anatomy Basis and Clinical Significance of Various Types of Abductor Hallucis Superior Margin Arterial Arcades
}

\author{
Bases Anatómicas e Importancia Clínica de Varios Tipos de \\ Arcos Arteriales del Margen Superior del Músculo Abductor del Hálux
}

Wei Tan",**; Wen-hua Huang*; Xu Li*** \& Ke Liu*

TAN, W.; HUANG, W.; LI, X. \& LIU, K. Anatomy basis and clinical significance of various types of abductor hallucis superior margin arterial arcades. Int. J. Morphol., 31(3):879-887, 2013.

SUMMARY: The aim of this study was to group arteries of arterial arch at the superior margin of the abductor hallucis muscle according to their constitutes and provide anatomical basis for reverse bifolicated flap based on it. The constitute, track-way and distribution of the artery, which supply the medial pedis flap, the medial plantar and the medial tarsal flap, especial the arterial arch at the superior margin of the abductor hallucis muscle were observed and analyzed on 81 lower limbs cast specimens and 2 fresh feet specimens. According to their constitute, arterial arch at the superior margin of the abductor hallucis muscle can be classified into 3 types: i) type I, It was constituted mainly by the branch of anterior medial malleolus artery and (or) the medial tarsal artery. ii) type II, It was constituted mainly by the superficial branch of the medial plantar artery; iii) type II, It was constituted mainly by the branch of anterior medial malleolus artery and the branch of medial tarsal artery anastomose with the superficial branch of the medial plantar artery, which was divided into two subtypes according to the different anastomosis of the artery: Type III 1, the type of anastomosed directly was about $48.2 \%$, type III 2 , The type of anastomosed indirectly was about $24.1 \%$. According to the constitute of arterial arch at the superior margin of the abductor hallucis muscle can be classified into three types: The type of anterior medial malleolus artery and medial tarsal artery, the type of superficial branch of the medial plantar artery and the type of mixed. For the type mixed, two subtypes can be classified according to the different anastomosis of the artery.

KEY WORDS: Abductor hallucis muscle; Arterial arch; Anterior medial malleolus artery; Medial tarsal artery; Superficial branch of the medial plantar artery; Blood vessel grouping.

\section{INTRODUCTION}

In recent years, with the promotion of minimallyinvasive consciousness in the surgical field and the innovation and application of minimally-invasive surgery, especially since application of medial plantar flap reported by Shanahan \& Gingrass (1979) and Reiffel \& Mccarthy (1980) successively and with the development of microsurgical techniques, medial plantar flap is gradually accepted due to its unique advantages and becomes the ideal flap of repairing forefoot cutaneous defect. Also, its applications are increasing (Gupta, 2007; Yoon et al., 2007; Zgonis et al., 2008; Vermeulen et al., 2011; Yang et al., 2011; $\mathrm{Gu} \&$ Jeong, 2012). For expanding the cutting range of medial plantar flap and extending vascular pedicle of flap, Chen et al. (1998), firstly named abductor superior margin arterial arcade in 1997 and proposed to use medial plantar flap with the arterial arcade as pedicle to multi-directionally transfer and repair foot skin defect. Subsequently, many scholars carried out investigations of medial plantar flap surgery with abductor hallucis superior margin arterial arcade as pedicle (Masquelet \& Romana, 1990; Schwabegger et al., 2003, 2005; Rath et al., 2009). However, the flap is limited in clinical promotion due to more blood vessel variations and lack of understandings. Therefore, we mainly observe the formation, running direction and distribution of abductor hallucis superior margin arterial arcade for providing an anatomic basis for the clinical application of reverse medial plantar flap with abductor hallucis superior margin arterial arcade as pedicle.

\footnotetext{
* Institute of Clinical Anatomy, Southern Medical University, Guangzhou, China.

** Department of Pediatric Orthopedics Center, the Third Affiliated Hospital of Southern Medical University, Guangzhou, China.
} 


\section{MATERIAL AND METHOD}

Observations of perfused specimens. In this study, $81 \mathrm{ca}-$ ses of good foot artery cast specimens and 2 natural-corrosion adult fresh leg specimens with artery perfused with red latex were selected. There were 39 cases of left feet and 44 cases of right feet. The distributions and running directions of medial anterior malleolar artery, medial tarsal artery, pedis superficial medial artery and its cutaneous branches and its anastomosis with hallux distal end and the formation of abductor hallucis superior margin arterial arcade were mainly observed.

Arterial perfusion and anatomy application. Two specimens of fresh adult foot after ankle disarticulation were selected. Deep fibular artery perforating branches were closed. Artery perfusion of foot was conducted respectively by carrying out perfusion of gelatin- lead oxide suspension via the catheters of anterior and posterior tibial arteries (Unger et al., 1995) for showing arterial distribution. Common hand surgical operation instruments and digital camera (Canon50D) were used. During anatomy, medial plantar artery, medial anterior malleolar artery, medial tarsal artery, medial plantar nerve and dorsal venous network medial branch and its branches were showed, and blood supply situations of the island flap with abductor hallucis superior margin arterial arcade as pedicle were observed.

\section{RESULTS}

Morphological characteristics of medial tarsal - and medial pedis - related arteries. Anterior tibial artery continued to become the dorsalis pedis artery at ankle, and medial tibial of this artery sent forth medial anterior malleolar artery, medial tarsal artery, the first dorsal metatarsal artery and deep plantar branch from the proximal to the distal (Fig. 1).

According to the observations of 83 cases of pedis cast specimens, occurrence rate of medial anterior malleolar artery was $100 \%$. There were three starting points: over intercondylar line (connection line between medial malleolus tip and lateral malleolus tip). The cases starting from anterior tibial artery accounted for $59.0 \%$ (49 cases); level with intercondylar line. The cases starting from intercondylar line accounted for $25.3 \%$ (21 cases); below intercondylar line. The cases starting from dorsalis pedis artery accounted for 15.7\% (13 cases) (Table I). After medial anterior malleolar artery sent forth from anterior tibial artery or dorsalis pedis artery, its main trunk inclined forward medial below extensor hallucis longus and ran towards the anterior medial (adjacent to medial anterior tibial tendon) to reach the inner side of navicular bone and medial cuneiform bone, and then divided into anterior branch and posterior branch nearby navicular tuberosity. Also, there were two accompanying veins. On the way, the main trunk of medial anterior malleolar artery sent forth 4 to 6 cutaneous branches distributing in the surfaces of anterior tibial tendon and extensor hallucis longus tendon, surrounding skins and subcutaneous tissues and 1 to 2 malleolar branches distributing in malleolus medialis and near skins and still sent forth fine branches distributing in huckle-bone, navicular bone and medial cuneiform bone. After medial tarsal artery sent forth dorsalis pedis artery, its main trunk slantways crossed the deep surface of extensor hallucis longus tendon and ran among the anterior inferior of anterior tibial tendon and the rear of extensor digitorum brevis tendon and then sent forth anterior branch and posterior branch nearby the inferior margin of medial cuneiform bone near. There were two accompanying veins. On the way, medial tarsal artery sent forth 3 to 4 cutaneous branches distributing in extensor hallucis longus tendon, anterior tibial tendon, extensor digitorum brevis tendon, periosteal surface and skins (Fig. 1). According to the differences of flap blood supply with medial anterior malleolar artery or medial tarsal artery as pedicle, Chen et al. divided it into three types. Posterior tibial artery ran from the near of medial malleolus into pelma and branched into medial pedisa rtery and lateral pedisa rtery at the abductor hallucis starting part of tarsal tunnel projection. Medial pedis artery sent forth deep branch and superficial branch of medial plantar artery at superior margin of abductor hallucis and proximal medial plantar gap. In addition, the superficial branch branched into medial branch and medial superficial arcade branch at the anterior navicular tuberosity. On the way, it sent forth 1 to 3 cutaneous branches which respectively anastomosed with posterior tibial artery,

Table I. The distribution of the original site of anterior medial malleolus artery.

\begin{tabular}{llrr}
\hline \multicolumn{1}{c}{ Origin } & Total & \multicolumn{1}{c}{ Left } & Right \\
\hline Above the line between medial malleolus and later almalleolus & $59.0 \%(49)$ & $26.5 \%(22)$ & $32.5 \%(27)$ \\
Equal the line between medial malleolus and lateral malleolus & $25.3 \%(21)$ & $16.9 \%(14)$ & $8.4 \%(7)$ \\
Under the line between medial malleolus and lateral malleolus & $15.7 \%(13)$ & $4.8 \%(4)$ & $10.8 \%(9)$ \\
Total & $100 \%(83)$ & $47.0 \%(39)$ & $53.0 \%(44)$
\end{tabular}




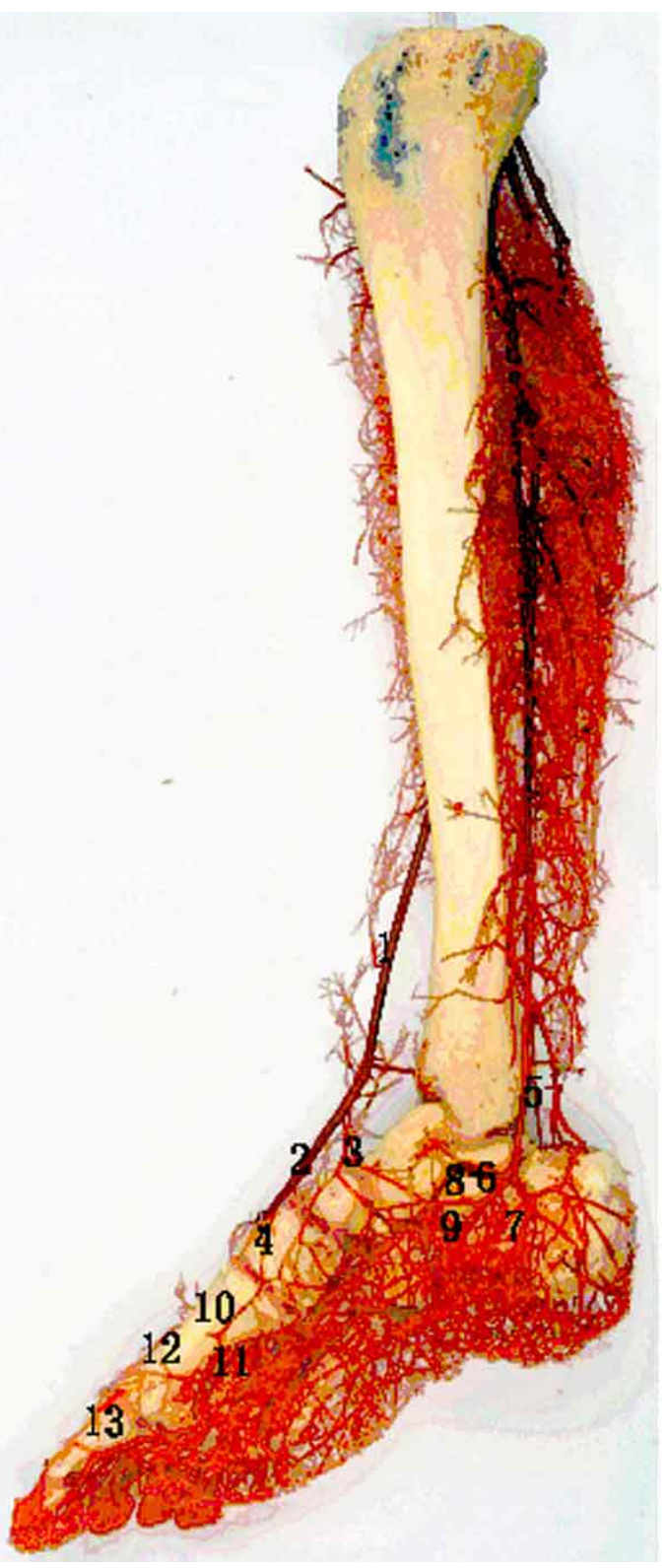

Fig. 1. The facies medialis view of fresh feet specimens perfused with red latex. 1) anterior tibial artery; 2) dorsal pedal artery; 3) anterior medial malleolus artery; 4) medial tarsal artery; 5) posterior tibial artery; 6) medial plantar artery; 7) lateral plantar artery; 8) calcaneal branch of lateral plantar artery; 9) superficial branch of medial plantar artery; 10) deep branch of medial plantar artery; 11) arterial arch at the superior margin of the hallucal abductor; 12) first plantar metatarsal artery; 13) artery on tibial side of first plantar metatarsal; 14) transverse hallucis artery.

calcaneal branch of posterior tibial artery, deep perforating branch of fibular artery or terminal branch to form the arterial rete. Between abductor hallucis and flexor digitorum brevis aponeurosis, lateral plantar artery ran, parallely to medial plantar nerve branches. Also, it continued to become arcus

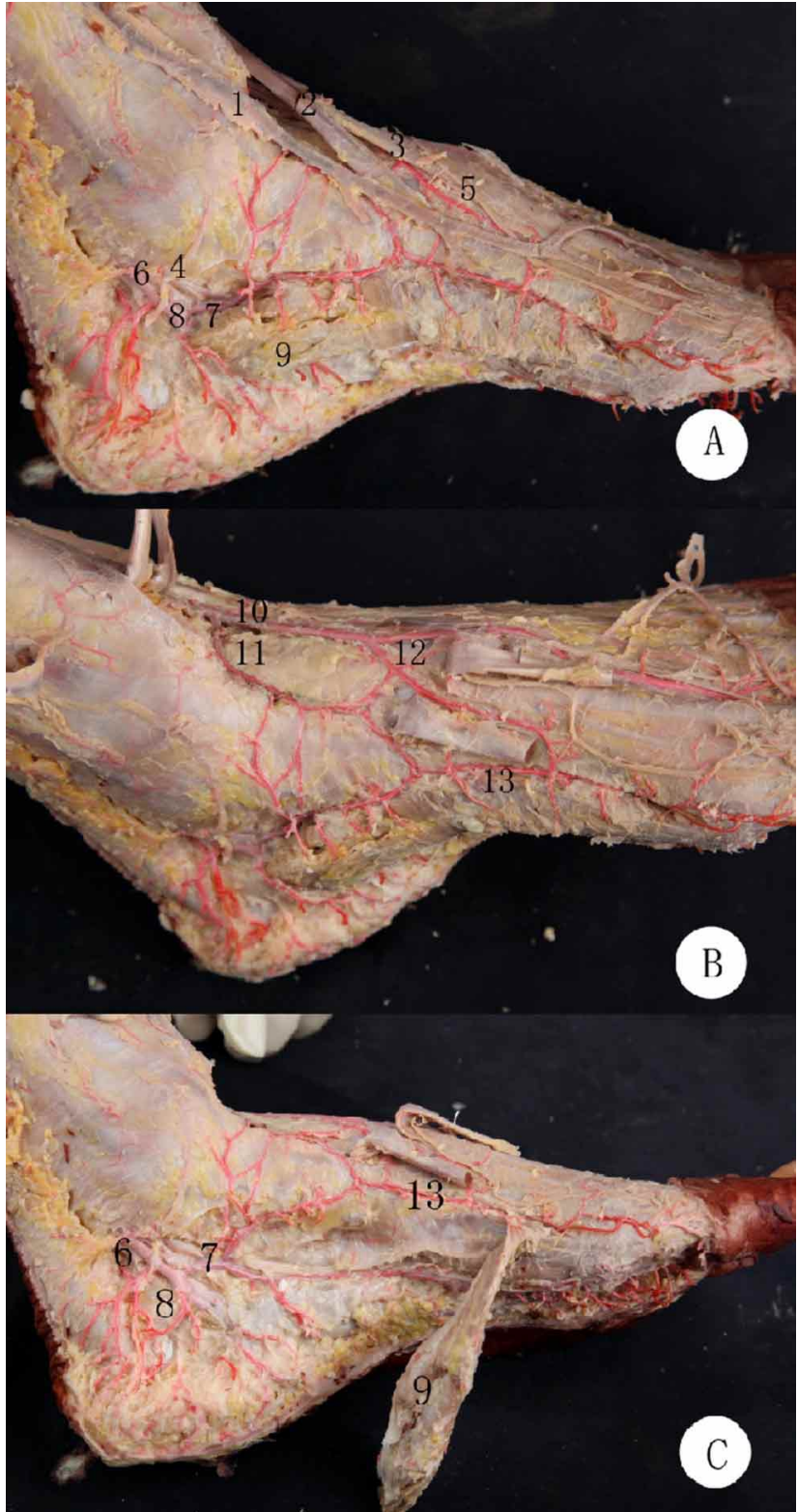

Fig. 2. The track-way and distribution of medialis artery of feet. A. The facies medialis view (not dissection of hallucal abductor); B. The dorsal view; $\mathrm{C}$. The facies medialis view (dissection of hallucal abductor). 1) great saphenous vein; 2) tibialis anterior; 3 ) extensor hallucis longus; 4) medial plantar nerve; 5) Medial dorsal neurocutaneous; 6) posterior tibial artery; 7) medial plantar artery; 8) lateral plantar artery; 9) hallucal abductor; 10) dorsal pedal artery; 11) anterior medial malleolus artery; 12) medial tarsal artery; 13) arterial arch at the superior margin of the hallucal abductor.

plantaris anastomosing with deep perforating branch set forth by dorsalis pedis artery at the anterior food and set forth the first metatarsal artery. This artery ran from the gap between the 1st and 2nd metatarsal bones to the 1st metatarsal neck and branched into tibial and fibular terminal trunk arteries. 
At the starting point of the first metatarsal artery, it sent forth the first metatarsal tibial artery. They jointly formed the " $4 \mathrm{Y}$ anastomosis" structure (Zgonis et al.). The first metatarsal tibial artery sent forth the ascending branch and descending branch. The ascending branch continued to form the superficial branch of medial hallux bottom artery. According to the sending forth position of superficial branch of medial hallux bottom artery, Mao et al. (2009), divided into it two types. Lateral plantar artery sent forth 4-6 muscular branches to nourish abductor hallucis and flexor digitorum brevis muscles. Mostly, there was only one accompanying vein. Medial anterior malleolar artery and medial tarsal artery and its anterior and posterior branches anastomosed with " $4 \mathrm{Y}$ " structure, superficial branch of medial hallux bottom artery and superficial branch of medial plantar artery to form abductor hallucis superior margin arterial arcade which became the shaft axis of medial tarsal and medial plantar arterial rete (Fig. 2).

Typing of abductor hallucis superior margin arterial arcade. According the formation ways, abductor hallucis superior margin arterial arcade was divided into three types (Table 2, Fig. 3).

Type I (Medial anterior malleolar artery and medial tarsal artery type): It was formed by medial anterior malleolar artery, medial tarsal artery and its branches. The anterior branch of medial anterior malleolar artery anastomosed with the posterior of medial tarsal artery at navicular wedge joint, and the posterior branch ran along the inferior margin of navicular bone towards the medial rear to tibial calcaneus and anastomosed with medial plantar artery and the superficial branch of medial plantar artery. The anterior branch of medial tarsal artery ran towards along medial cuneiform bone and the first metatarsal tibial margin and anastomosed with the first metatarsal artery, plantar perforating branch, hallux transverse artery and superficial branch of medial hallux bottom artery at Medial hallux bottom. The posterior branch anastomosed with the anterior branch of medial anterior malleolar artery at navicular wedge joint. This type of medial plantar artery was short and small, and its distribution range was smaller. Also, it didn't anastomose with other artery formations. This type of cases accounted for $22.9 \%$ of total pedisartery cast specimens (19 cases, including 7 left cases and 12 tight cases) (Fig. 3 A).

Type II (superficial branch type of medial plantar artery): It was mainly formed by the superficial branch of medial plantar artery. Medial superficial branch of medial plantar artery ran towards the first metatarsal bone along navicular bone and inferior margin of medial cuneiform bone to lateral hallux bottom and anastomosed with the first metatarsal artery, plantar perforating branch, hallux transverse artery and superficial branch of medial hallux bottom artery. Medial superficial arcade branch ran along navicular bone, internal inferior margin of medial cuneiform bone and bended forward outboard at the middle of phalanx to form arcuate shape and sent forth 2 to 3 branches respectively joining plantar metatarsal artery. Medial anterior malleolar artery and anterior tibial artery of medial tarsal artery were fine and short and their distribution range was small. Also, they didn't anastomose with superficial branch of medial plantar artery and cutaneous branches sent forth by it. This type of cases accounted for $3.6 \%$ of total pedisartery cast specimens ( 3 cases including 2 left cases and 1 right case) (Fig. 3 B).

Type III (mixed type): it was mainly formed by anastomoses of superficial branch of medial plantar artery with medial anterior malleolar artery and medial tarsal artery. According to different anastomosis forms, it could be divided into two subtypes.

Subtype III 1 (direct anastomosis type): After medial anterior malleolar artery and medial tarsal artery were sent forth, they directly anastomosed with the superficial branch of medial plantar artery and its branches. The superficial branch of medial plantar artery and its branches directly anastomosed with medial anterior malleolar artery and medial tarsal artery at navicular bone, medial cuneiform bone and first metatarsal tibial side to form abductor hallucis superior margin arterial arcade. This type of cases accounted for $48.2 \%$ of total pedisartery cast specimens (40 cases including 22 left cases and 18 right cases) (Fig. 3 C).

Subtype III 2 (indirect anastomosis type): After medial anterior malleolar artery and medial tarsal artery were sent forth, they directly anastomosed with the superficial branch of medial plantar artery and its branches to form a ring. After medial anterior malleolar artery and aortic trunk of medial tarsal artery were sent forth by anterior tibial artery or/and dorsalis pedis artery from different angles, they ran on the surfaces of navicular bone and medial cuneiform bone to the inferior margin of navicular tuberosity and medial cuneiform bone. Medial anterior malleolar artery and medial tarsal artery respectively sent forth the anterior and posterior branches which respectively anastomosed with medial branches and medial superficial arcade branches sent forth by superficial branch of medial plantar artery to construct the ring abductor hallucis superior margin arterial arcade. The key of this type lay in that arterial ring components should contain the superficial branch of medial plantar artery. This type of cases accounted for $24.1 \%$ of total pedisartery cast specimens (20 cases including 8 left cases and 12 right cases) (Fig. 3 D). 


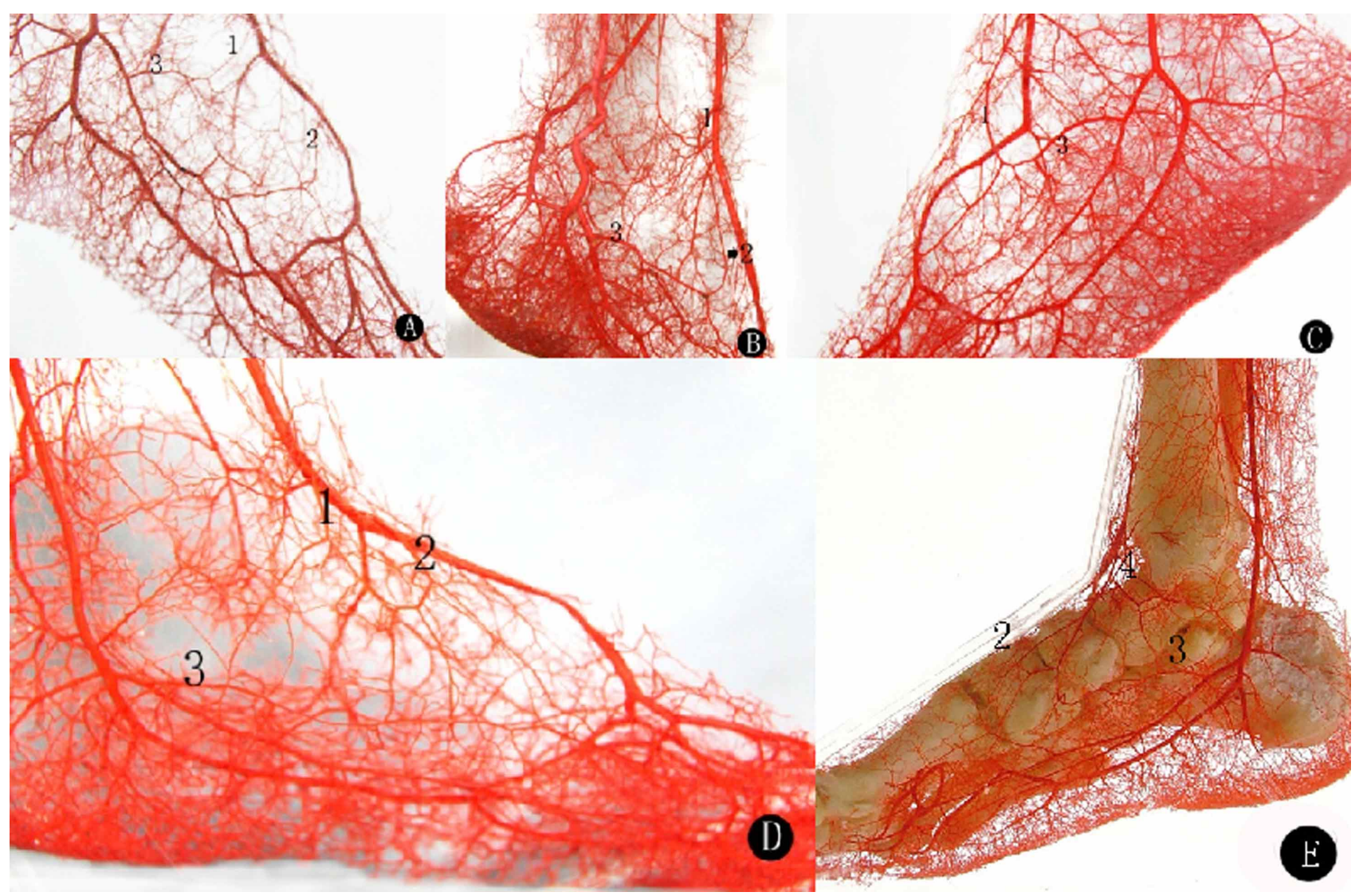

Fig. 3. The grouping of arterial arch at the superior margin of the hallucal abductor. 1) anterior medial malleolus artery; 2) medial tarsal artery; 3) superficial branch of medial plantar artery; 4) peroneal perforator artery. A: Type I. It was constituted mainly by the branch of anterior medial malleolus artery and(or) the medial tarsal artery. B: Type II. It was constituted mainly by the superficial branch of the medial plantar artery. C: Type III 1 (anastomosed directly) It was constituted mainly by the arterial arch from the anterior medial malleolus artery and (or) the medial tarsal artery anastomose directly with the superficial branch of the medial plantar artery. D: Type III 2 (anastomosed indirectly). It was constituted mainly by the arterial arch from the arterial circle, which anastomosed by the branch of anterior medial malleolus artery, the branch of medial tarsal artery and the superficial branch of the medial plantar artery with each other. E: Particular case. It was constituted mainly by the superficial branch of the medial plantar artery anastomose with fibular artery, which instead of dorsalis pedis artery.
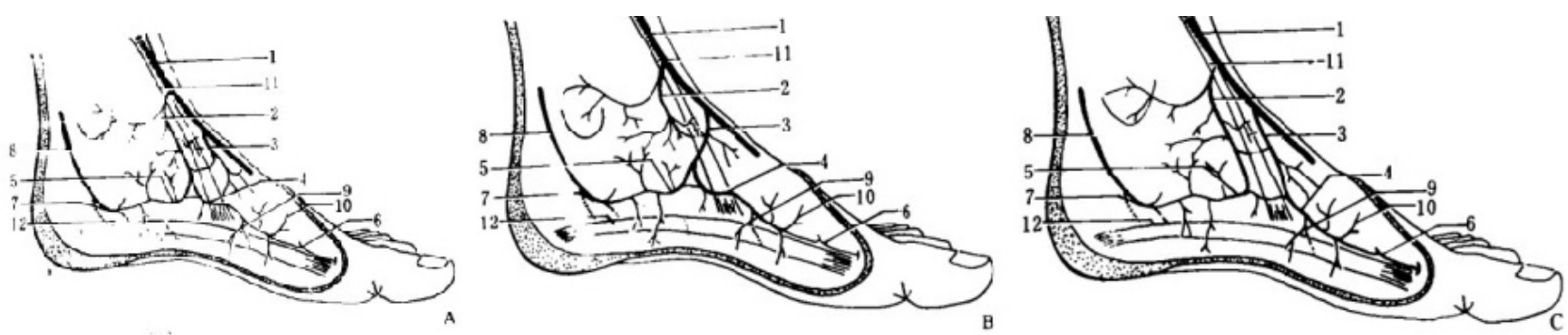

Fig. 4. The classification of blood supply of medial plantar flap. 1) Anterior tibial artery; 2) Anterior medial malleolus artery; 3) Medial tarsal artery; 8) Posterior tibial artery; 11) dorsal pedal artery. A: Type i. It was constituted mainly by the branch of anterior medial malleolus artery. B: Type ii. It was constituted mainly by he medial tarsal artery. C: Type iii. It was constituted mainly by the anterior medial malleolus artery and the medial tarsal artery. 
Table II. The grouping of arterial arch at the superior margin of the hallucis abductor

\begin{tabular}{lccc} 
muscle. & Total & Left & Right \\
\hline Type & & & \\
\hline Type_I & $22.9 \%(19)$ & $8.4 \%(7)$ & $14.5 \%(12)$ \\
Type II & $3.6 \%(3)$ & $2.4 \%(2)$ & $1.2 \%(1)$ \\
& & & \\
Type III & $72.4 \%(60)$ & $36.2 \%(30)$ & $36.2 \%(30)$ \\
Type III & & $26.5 \%(22)$ & $21.7 \%(18)$ \\
Type III & & $9.6 \%(8)$ & $14.5 \%(12)$ \\
& $24.1 \%(20)$ & & \\
Particular case & $1.2 \%(1)$ & $0.0 \%(0)$ & $1.2 \%(1)$ \\
Total & $100 \%(83)$ & $47.0 \%(39)$ & $53.0 \%(44)$ \\
\hline
\end{tabular}

\section{DISCUSSION}

Pedis vessels are mainly from anterior tibial artery, posterior tibial artery, peroneal artery and its perforating branch, and they are also involved in pedis blood supply. Posterior tibial artery runs to pelma via tarsal tunnel and branches into medial plantar artery and lateral plantar artery (Hidalgo \& Shaw, 1986). Among them, lateral plantar artery runs to the proximal first metatarsal gap and anastomoses with plantar deep branch of dorsalis pedis artery to form arcus plantaris. Anterior tibial artery runs to dorsal pedis artery via ankle joint and its various branches anastomose each other at the inside and outside sides of foot. The descending branch of fibular artery perforating branch is involved in anastomosis of arterial rete (Hidalgo \& Shaw, 1986). In this study, among 83 cases of observed specimens, occurrence rate of medial anterior malleolar artery was $100 \%$ and the cases starting from over, on and below intercondylar line (connection line between medial malleolus tip and lateral malleolus tip) respectively accounted for 59.0\%, $25.3 \%$ and $15.7 \%$. Occurrence rate of medial tarsal artery was $100 \%$, and all starts from below intercondylar line, which was close to the previous reports (Masquelet et al., 1988; Amarante \& Reis, 1990). It is suggested that medial anterior malleolar artery and medial tarsal artery are main branches of anterior tibial artery and dorsal pedis artery and sending forth positions of medial anterior malleolar artery are inconstant, while most positions are over intercondylar line. Most cases are sent forth by anterior tibial artery. However, medial tarsal artery is from dorsal pedis artery, and all start from below intercondylar line.

Blood supply of pedis and tarsal medial flaps is very plentiful, and there many variations. Also, vascular routing and anastomosis is complex. Since Chen et al., found and named abductor hallucis superior margin arterial arcade according to observations of medial pedisflap blood supply, many scholars have conducted relevant studies. Mao et al., reported that abductor hallucis superior margin arterial arcade was formed by the anastomoses with medial anterior malleolar artery, medial tarsal artery and the anterior and posterior branches sent forth by it with superficial branch of medial hallux bottom artery and superficial branch of medial plantar artery (Schwabegger et al., 2003, 2005; Macchi et al., 2005; Rath et al.). In addition, some scholars called abductor hallucis superior margin arterial arcade as medial pedis vascular chain. Li Changhui et al., found that medial pedis vascular chain was constructed by medial pedis margin artery, medial tarsal artery, medial branch of deep branch of medial plantar artery and " $4 \mathrm{Y}$ " (Zgonis et al.). In this study, the type (mixed type) jointly formed by anastomoses of medial anterior malleolar artery, medial tarsal artery and superficial branch medial plantar artery accounted for $72.4 \%$. III1 subtype (direct anastomosis) cases accounted for $48.2 \%$ and III2 subtype (indirect anastomosis) cases accounted for $24.1 \%$. According to Chen et al., typing of medial pedis flap blood supply, these two types were respectively divided three types: medial anterior malleolar artery type, medial tarsal artery type, medial anterior malleolar artery type and medial tarsal artery type. Medial anterior malleolar artery and/or medial tarsal artery and its cutaneous branches formed type I. Medial anterior malleolar artery and/or medial tarsal artery type accounted for $22.9 \%$. According to Chen et al., typing of medal pedis flap blood supply, this type was divided into three types (Fig. 4): medial anterior malleolar artery type, medial tarsal artery type, medial anterior malleolar artery and medial tarsal artery type. The superficial branch of medial plantar artery and its cutaneous branches formed type 
II. The superficial branch type of medial plantar artery accounted for $3.6 \%$. It is suggested that pedis and tarsal medial flaps are of circular blood supply. Also, abductor hallucis superior margin arterial arcade is called as "medial pedis vascular chain", mainly formed by anastomoses of anterior tibial artery and it branches and posterior tibial artery and its branches, and it is the "bridge" of blood supply of pedis and tarsal medial flaps and becomes the central axis of medial pedis flap, medial plantar flap and medial tarsal flap. This arterial arcade is formed by mutual anastomoses of medial pedis artery, medial tarsal artery and its branches to construct the divergent vascular network of pedis medial tarsal artery with arterial arcade as the center. In this study, abductor hallucis superior margin arterial arcade wasn't further typed to according to carry out observation, measurement and statistics of the relevant anatomical data according to Chen et al., typing of medial pedis flap blood supply due to the limited specimen number. In addition, it was still found that fibular artery perforating branch replaced dorsalis pedis artery, and between perforating branch and anterior tibial artery, fine branches connected to form the arterial ring. Also, the perforating branch anastomosed with posterior tibial artery and medial calcaneal cutaneous branch to form the arterial rete, and it anastomosed with medial plantar artery superficial branch to form abductor hallucis superior margin arterial arcade. This was type III dorsalis pedis artery (Kishman et al., 2009), and this type of variations accounted for $1.2 \%$.

Blood supply of medial pedis flap, medial plantar flap and medial tarsal flap is very plentiful, and abductor hallucis superior margin arterial arcade acts as an important blood supply artery of medial pedis flap, medial plantar flap and medial tarsal flap. The type mainly formed by medial anterior malleolar artery, medial tarsal artery and its main branches is called as medial tarsal artery type of medial anterior malleolar artery. Its cases accounts for $22.9 \%$ of total number. Medial anterior malleolar artery and the anterior and posterior branches of medial tarsal artery runs at the superior margin of abductor hallucis muscle and connect medial hallux bottom artery superficial branch, hallux transverse artery and tibial hallux bottom inherent artery through the tibial ascending branch of first metatarsal artery to nourish medial pedisflap, medial plantar flap and medial tarsal flap. In this type, as medial plantar artery superficial branch is fine and short, and it doesn't anastomose with medial anterior malleolar artery and medial tarsal artery to jointly form abductor hallucis superior margin arterial arcade. Therefore, in case of clinical application of reverse medial pedis flap with abductor hallucis superior margin arterial arcade as pedicle, this type will play an important role in the formation of abductor hallucis superior margin arterial arcade. The correlation of abductor hallucis superior margin arterial arcade with superficial branch of medial plantar artery and its branches shall be concerned because it will provide an idea for flap cutting. When this type of flap takes the area nearby the middle point of intercondylar line as rotating point, it transfers forwards and backwards with vascular pedicle as medial anterior malleolus or medial tarsal vessel to cell secular to repair Dorsal and medial malleolus surrounding skin defect. It is similar to the traditional medial pedis artery flap (Uygur et al., 2008; Unglaub et al., 2010). When the first metatarsal neck level or proximal phalanx hallux midpoint acts as the rotating point of flap and vascular pedicle acts as abductor hallucis superior margin arterial arcade, the flap transfers forwards to repair anterior pedis skin defect.

The superficial branch of medial plantar artery runs at the superior margin of abductor hallucis muscle and anastomoses with superficial branch of medial hallux bottom artery, hallux transverse artery and tibial hallux bottom inherent artery at the tibial side of hallux bottom to form abductor hallucis superior margin arterial arcade. In this case, the type is called as medial plantar artery superficial branch type, and this type of cases accounts for $3.6 \%$ of total cases. The superficial branch of medial plantar artery sends forth cutaneous branch anastomosing with the deep branch of medial plantar artery to form arterial rete at the middle point of superior margin of abductor hallucis and sends forth muscular branch to nourish abductor hallucis muscle. For this type, as medial anterior malleolar artery and medial tarsal artery are fine and short and distribution range is small, it can't anastomose with the superficial branch of medial plantar artery to form abductor hallucis superior margin arterial arcade. Although the cases of abductor hallucis superior margin arterial arcade formed only by the superficial branch of medial plantar artery are very rare, this must be concerned in vascular repair and reconstruction and flap design. This type of flap is similar to the traditional medial plantar flap with medial plantar artery superficial branch as pedicle. The applied anatomy designed by Koman et al. (1985), Huang et al. (2010); Sun et al. (2010) and Yokoyama et al. (2010) which anastomosed with medial plantar flap transplant to repair hand defect created a new clinical operation mode to apparently increase clinical curative effect. Chen et al., firstly named abductor hallucis superior margin arterial arcade and proposed to use medial plantar flap with the arterial arcade as pedicle to multi-directionally transfer and repair foot skin defect, which created a new clinical operation mode to apparently increase clinical curative effect. Secondly, this artery sends forth many perforating branches on the surface of abductor hallucis. Therefore, it is feasible to design abductor hallucis muscle cutaneous flap with this arterial arcade as pedicle to repair anterior pedis bone defect, bone non-union and other refractory diseases. At the same time, 
abductor hallucis arterial arcade connects deep branch of medial plantar artery through superficial branch of medial plantar artery. In clinic, medial plantar flap with deep branch of medial plantar artery as "Y" shape vascular pedicle of blood supply source is designed for expanding application range of flap according to anatomical features of medial plantar artery.

The superficial branch of medial plantar artery and its cutaneous branches anastomose with medial anterior malleolar artery and medial tarsal artery to form a branch at the superior margin of abductor hallucis muscle and anastomose with medial hallux bottom artery superficial branch, hallux transverse artery and tibial hallux bottom inherent artery at the tibial side of hallux bottom to form abductor hallucis superior margin arterial arcade. In this case, this type is called as the mixed type. This type of flap is the main blood supply form of medial plantar flap, accounting for $72.4 \%$ of total number. According to different anastomosis forms of superficial branch of medial plantar artery and medial anterior malleolar artery with medial tarsal artery, it can be divided into two subtypes (direct anastomosis type and indirect anastomosis type). Therefore, it is necessary to observe the situations of medial plantar artery superficial branch anastomosing with medial anterior malleolar artery and medial tarsal artery in case of flap design in order to provide an idea for the design of expanding flap cutting range, looking for the optimal operation scheme and extending flap vascular pedicle. As the medial plantar and medial pedis combination flap with abductor hallucis superior margin arterial arcade as pedicle is designed, it is feasible to consider several schemes: Use distal anastomosis branch of abductor hallucis superior margin arterial arcade as pedicle to design the medial plantar and medial pedal large combination flap to repair dorsal and anterior plantar skin defect and use medial plantar artery superficial branch or medial anterior malleolus and medial tarsal artery as pedicle to design medial pedis and medial plantar large combination flap to repair heel and ankle defect. For example, Mao et al., used anastomosis branch of abductor hallucis superior margin arterial arcade to design the large flap with superficial branch of medial hallux bottom artery and deep branch of medial plantar artery as pedicle to repair large area of skin defect. Use abductor hallucis superior margin arterial arcade, medial anterior malleolar artery, medial tarsal artery and medial plantar artery superficial branch as pedicle to design multiblade flap; partial medial plantar artery superficial branch anastomoses with medial anterior malleolar artery and the anterior and posterior branches of medial tarsal artery at the superior margin of abductor hallucis to form a ring. For the indirect anastomosis type, parts of this annular artery construct the proximal segment of abductor hallucis superior margin arterial arcade. Therefore, it is feasible to cut any of annular anastomosis part to extend vascular pedicle of flap.

\section{ACKNOWLEDGMENTS}

This study was supported by National high technology research and development program (863 program) project (NO: S2012AA022803).

TAN, W.; HUANG, W.; LI, X. \& LIU, K. Bases anatómicas e importancia clínica de varios tipos de arcos arteriales del margen superior del músculo abductor del hálux. Int. J. Morphol., 31(3):879-887, 2013.

RESUMEN: El objetivo fue clasificar las arterias de arco arterial del margen superior del músculo abductor del hálux según su constitución, y proporcionar una base anatómica para el colgajo bilobulado reverso basado en él. La constitución, recorrido y distribución de las arterias que suministran los colgajos pedicular medial, plantar medial y medial del tarso, en especial el arco arterial del margen superior del músculo abductor del hálux fueron observados y analizados en 81 modelos de miembros inferiores y 2 pies frescos. De acuerdo con su constitución, el arco arterial del margen superior del músculo abductor del hálux se pueden clasificar en 3 tipos: i) tipo I, constituido principalmentepor la rama de la arteria anterior del maléolo medial y/o la arteria medial del tarso. ii) tipo II, constituido principalmente por la rama superficial de la arteria plantar medial, iii) tipo III constituido principalmente por la rama de la arteria maleolar medial anterior y la rama de la anastomosis de la arteria tarsiana medial de la rama superficial de la arteria plantar medial, que se divide en 2 subtipos diferentes de acuerdo con el tipo de anastomosis: tipo III 1, una anastomosis directa que se observó en el 48,2\%, y tipo III 2, una anastomosis indirecta observada en aproximadamente el $24,1 \%$ de los casos. Según la constitución, el arco arterial del margen superior del músculo abductor del hálux se puede clasificar en 3 tipos: el tipo de arteria anterior del maléolo medial y la arteria tarsiana medial, el tipo de rama superficial de la arteria plantar medial y el tipo mixto. En el tipo mixto, pueden ser clasificados 2 subtipos de acuerdo a la diferente anastomosis de la arteria.

PALABRAS CLAVE: Músculo abductor del hálux; Arco arterial; Arteria anterior del maléolo medial; Arteria tarsiana medial; Rama superficial de la arteria plantar medial; Clasificación de vasos sanguíneos. 


\section{REFERENCES}

Amarante, J. \& Reis, J. The medial plantar flap. Plast. Reconstr. Surg., 86(5):1041-2, 1990.

Chen, M. L.; Shi, Z. Y.; Yao, N. Z.; Yi, W. G. \& Yang, X. Q. Arterial anatomy of the medialis pedis flap. Chin. J. Clin. Anat., 16(2):107-9, 1998.

Gu, J. H. \& Jeong, S. H. Radical resection of a venous malformation in middle finger and immediate reconstruction using medial plantar artery perforator flap: a case report. Microsurgery, 32(2):148$52,2012$.

Gupta, A. The versatile medial plantar artery and its flaps. Ann. Plast. Surg., 58(3):348, 2007.

Hidalgo, D. A. \& Shaw, W. W. Anatomic basis of plantar flap design. Plast. Reconstr. Surg., 78(5):627-36, 1986.

Huang, S. H.; Wu, S. H.; Lai, C. H.; Chang, C. H.; Wang, C. H.; Lai, C. S.; et al. Free medial plantar artery perforator flap for finger pulp reconstruction: report of a series of 10 cases. Microsurgery, 30(2):118-24, 2010.

Kishman, L.; Malin, D.; Nerone, V. \& Siesel, K. Clinical implications of peroneal artery variation. Foot Ankle Spec., 2(3):135-9, 2009.

Koman, L. A.; Weiland, A. J. \& Moore, J. R. Toe-to-hand transfer based on the medial plantar artery. J. Hand Surg. Am., 10(4):5616, 1985.

Macchi, V.; Tiengo, C.; Porzionato, A.; Stecco, C.; Parenti, A.; Mazzoleni, F.; et al. Correlation between the course of the medial plantar artery and the morphology of the abductor hallucis muscle. Clin. Anat., 18(8):580-8, 2005.

Mao, H. J.; Yin, W. G. \& Hi, Z. Y. Applied anatomy of the reverse medialis pedis island flap. Chin. J. Clin. Anat., 27(3):279-82, 2009.

Masquelet, A. C. \& Romana, M. C. The medialis pedis flap: a new fasciocutaneous flap. Plast. Reconstr. Surg., 85(5):765-72, 1990.

Masquelet, A. C.; Penteado, C. V.; Romana, M. C. \& Chevrel, J. P. The distal anastomoses of the medial plantar artery: surgical aspects (2.10.1987). Surg. Radiol. Anat., 10(3):247-9, 1988.

Rath, B.; Notermans, H. P.; Frank, D.; Walpert, J.; Deschner, J.; Luering, C. M.; et al. Arterial anatomy of the hallucal sesamoids. Clin. Anat., 22(6):755-60, 2009.

Reiffel, R. S. \& McCarthy, J. G. Coverage of heel and sole defects: A new subfascial arterialized flap. Plast. Reconstr. Surg., 66(2):25060, 1980.

Schwabegger, A. H.; Shafighi, M. \& Gurunluoglu, R. Versatility of the abductor hallucis muscle as a conjoined or distally-based flap. J. Trauma, 59(4):1007-11, 2005.

Schwabegger, A. H.; Shafighi, M.; Harpf, C.; Gardetto, A. \& Gurunluoglu, R. Distally based abductor hallucis muscle flap: anatomic basis and clinical application. Ann. Plast. Surg., 51(5):505-8, 2003.

Shanahan, R. E. \& Gingrass, R. P. Medial plantar sensorg flap for coverage heel defects. Plast. Reconstr. Surg., 64(3):295-8, 1979.

Sun, W.; Wang, Z.; Qiu, S.; Guan, S.; Hu, Y.; Zhu, L.; et al. Repair of soft-tissue defects on volar aspect of fingers with medial plantar venous flap. Zhongguo Xiu Fu Chong Jian Wai Ke Za Zhi, 24(1):50-2, 2010.

Unger, E. C.; Schilling, J. D.; Awad, A. N.; McIntyre, K. E.; Yoshino, M. T.; et al. MR angiography of the foot and ankle. J. Magn. Reson. Imaging, 5(1):1-5, 1995.

Unglaub, F.; Wolf, M. B.; Dragu, A.; Forst, J.; Horch, R. E. \& Kneser, U. Reconstruction of a child's forefoot defect using a distally based pedicled medial plantar flap. Arch. Orthop. Trauma Surg., 130(2):155-8, 2010.

Uygur, F.; Duman, H.; Ulkür, E.; Noyan, N. \& Celiköz, B. Reconstruction of distal forefoot burn defect with retrograde medial plantar flap. Burns, 34(2):262-7, 2008.

Vermeulen, K.; Neven, E.; Vandeputte, G.; Van Glabbeek, F. \& Somville, J. Relationship of the Scarf valgus-inducing osteotomy of the calcaneus to the medial neurovascular structures. Foot Ankle Int., 32(5):S540-4, 2011.

Yang, D.; Yang, J. F.; Morris, S. F.; Tang, M. \& Nie, C. Medial plantar artery perforator flap for soft-tissue reconstruction of the heel. Ann. Plast. Surg., 67(3):294-8, 2011.

Yokoyama, T.; Tosa, Y.; Hashikawa, M.; Kadota, S. \& Hosaka, Y. Medial plantar venous flap technique for volar oblique amputation with no defects in the nail matrix and nail bed. $J$. Plast. Reconstr. Aesthet. Surg., 63(11):1870-4, 2010.

Yoon, E. S.; Kim, D. W.; Chun, D.; Dhong, E. S.; Koo, S. H.; Park, S. $\mathrm{H}$.; et al. An anatomic study and clinical application of medial pedis flap in Asians. Ann. Plast. Surg., 58(5):517-22, 2007.

Zgonis, T.; Roukis, T. S.; Stapleton, J. J. \& Cromack, D. T. Combined lateral column arthrodesis, medial plantar artery flap, and circular external fixation for Charcot midfoot collapse with chronic plantar ulceration. Adv. Skin Wound Care, 21(11):521-5, 2008.

\section{Correspondence to: \\ Wen-hua Huang \\ Institute of Clinical Anatomy \\ Southern Medical University \\ Guangzhou 510515 \\ CHINA}

Tel: 020-61648183

Received: 08-05-2012

Accepted: 11-12-2012

Email: wenhuahuangcn@yeah.net 